\title{
Assessment and development of bone preparation for radiocarbon dating at HEKAL
}

\author{
István Major ${ }^{1}$, István Futó1, János Dani², Orsolya Cserpák-Laczi², Mihály Gasparik², A. J. \\ Timothy Jull ${ }^{1,4,5}$, Mihály Molnár ${ }^{1}$ \\ ${ }^{1}$ Isotope Climatology and Environmental Research Centre (ICER), Institute for Nuclear Research, Hungarian \\ Academy of Sciences (MTA ATOMKI), Bem tér 18/c. H-4026, Debrecen, Hungary. \\ ${ }^{2}$ Déri Museum, Déri tér 1, H-4026 Debrecen, Hungary \\ ${ }^{3}$ Hungarian Natural History Museum, Department of Paleontology and Geology, Pf. 137, H-1431 Budapest, \\ Hungary. \\ ${ }^{4}$ Department of Geosciences, University of Arizona, 1118 East Fourth St., Tucson, AZ 85721, USA. \\ ${ }^{5}$ AMS Laboratory, Department of Physics, University of Arizona, Tucson, AZ 85721, USA.
}

\begin{abstract}
Bone is one of the most complex sample materials used for radiocarbon dating. The installation of the EnvironMICADAS AMS at HEKAL (department of ICER) in 2011 required the adoption of new sample preparation techniques for small bones samples. Since then, hundreds of procedural background and known-age bones have been processed using our modified Longin method (MLM) and dated along with unknown samples. Their results are used in this study to assess the reproducibility of our current bone preparation method and the real uncertainty of the final age result. In addition, using the background samples, which are included in each bone measurement batch, blank correction of the unknown samples could also be performed. The mean $\mathrm{F}^{14} \mathrm{C}$ value of our bone blanks is better than $0.005(\sim 42.500$ BP) alongside $0.0013 \mathrm{SD}$. Good reproducibility was confirmed by the results of the laboratory known-age bone as well, where the standard deviation of the mean value is better than 0.0025. In addition, the results of the three bone samples used in an ultrafiltration (UF) test study have not shown notable differences from the ones obtained by our current protocol in $1 \sigma$ uncertainty range but more experiments will be performed in the near future.
\end{abstract}

Keywords: blank correction, bone preparation, radiocarbon, quality assurance, ultrafiltration

\section{Introduction}

Human and animal archaeological remains (bone, tooth, ivory and antler) are very complex materials that are used in the radiocarbon $\left({ }^{14} \mathrm{C}\right)$ dating technique. Bones are basically built up by an organic collagen (an amino acid mixture composed mainly of hydroxyproline) and an inorganic mineral (calcium phosphate containing structural carbonate) fraction. Although carbon from the mineral fraction might be suitable for ${ }^{14} \mathrm{C}$ dating (Saliége et al. 1995), extraction of the organic collagen fraction is the most preferred method in dating of bones (Longin 1971). Fresh bone contains about $20 \mathrm{wt} \%$ collagen but this value drops steadily during burial and its chemical composition can be altered significantly due to diagenetic processes and ambient carbon-containing compounds such as fulvic and humic acids, polysaccharides, lipids and carbonates (van Klinken and Hedges 1995).

The earliest ${ }^{14} \mathrm{C}$ dates were obtained on whole bones, thus the dates were often inaccurate, compared to the associated dates on charcoal. Longin (1971) was the first who proposed the separation of the acid-insoluble collagen from the inorganic fraction, using a weak acid decalcification wash. Later, an additional base wash step (using diluted $\mathrm{NaOH}$ ) was introduced into the protocol to remove humic substances (Arslanov and Svezhentsev 1993). Although this protocol provides collagen that generally yields more accurate ${ }^{14} \mathrm{C}$ dates, $\mathrm{NaOH}$ 
may significantly decreases the collagen yield, and does not completely remove organic contaminants (Brown et al. 1988). Since then, other improved methods for purification of collagen have been developed (e.g. ninhydrin method, step combustion technique or protein remnant cleaning by ion-exchange columns) but ultrafiltration is currently the most popular protocol for collagen purification (Bronk Ramsey et al., 2004). Ultrafiltration separates collagen compounds with high molecular weight (HMW, $>30 \mathrm{kD}$ ) from low molecular weight $(\mathrm{LMW},<30 \mathrm{kD}$ ) fraction. The HMW fraction is expected to contain intact bone collagen, while LMW compounds include broken collagen chains and soil-derived organic compounds. However, numerous studies have demonstrated that the glycerol used to keep the cellulose membrane of the ultrafilter moist may contain old or post-bomb organic carbon, of which removing might be problematic (Hüls et al. 2007, 2009). Nonetheless, according to Higham et al. (2006), using ultrafiltration can be strongly associated with the reduction of the ${ }^{14} \mathrm{C}$ background limit of ancient bones, which has made the investigation of bone background limit and reproducibility a major topic in many laboratories (Wood et al., 2010; Naysmith et al., 2017). For the purpose of background determination, ${ }^{14} \mathrm{C}$ laboratories have begun to use ${ }^{14} \mathrm{C}$ free infinite aged bones, which are treated in parallel with the unknown samples to identify any contamination-derived ${ }^{14} \mathrm{C}$ introduced during the chemical pretreatment, $\mathrm{CO}_{2}$ conversion or graphitization sub-steps (Dunbar et al., 2017). The vast majority of bone samples submitted for dating are less than one ${ }^{14} \mathrm{C}$ half-life in age, thus younger known-age samples are also worth studying to monitor the variability and uncertainty of the ${ }^{14} \mathrm{C}$ date determinations. Subsequently, when a large number of results of repeated samples have already been collected, statistical methods may also help to reveal the long-term reproducibility of the measurements, in addition, to determine the most adequate blank correction procedure.

The two main purpose of this study is to (1) gain a better understanding of the background and reproducibility of our modified Longin (MLM) bone preparation protocol and suggest an adequate blank correction procedure, and (2) additionally, evaluate and establish an ultrafiltration protocol (UF) at our laboratory, using our internal standard bone samples of different ages and preservation.

\section{Materials and methods}

Since the start of the AMS laboratory at the Hertelendi Laboratory of Environmental Studies (HEKAL, Department of the Isotope Climatology and Environmental Research Centre, ICER), numerous internal procedural blank and known-age bones have been prepared. Our study uses 82 background and 70 known-age measurements carried out between February 2016 and September 2018 to evaluate mathematically the background and uncertainty of our current protocol. The blank correction process can also be applied to unknown samples. Usually, only the uncertainty of the ${ }^{14} \mathrm{C}$ measurement is given in analysis reports, which, despite the instrument blank correction and normalization, may not include the standard deviation (SD) related to the sample pretreatment and processing. At HEKAL, background bones with infinite ${ }^{14} \mathrm{C}$ age are routinely prepared and measured in each AMS measurement batch, which have resulted in a large number of dates over the last two and a half year. Although, our bone preparation protocol appears to be adequate based on the dates of blank and known-age sample, we have recognized the need for the continuous development. Hence, we inserted an ultrafiltration step into our current bone process protocol and tested it on three bone samples covering a wide range of ages from modern to blank. The quality of collagen was monitored by carbon and nitrogen stable isotope ratio, in addition $\mathrm{C} / \mathrm{N}$ ratio measurements. 
As internal procedural standards, three different blank and one known-age sample applied at our laboratory were studied. All the three blank samples were classified and kindly provided by Mihály Gasparik (Hungarian Natural History Museum, Budapest). The first two samples (ProB1_1 and ProB1_2) belonging to a steppe bison (Bison priscus) were found in the same gravel pit in 2012. The third bone blank (ProB1_3) originates from a complete mandible of a woolly mammoth (Mammuthus primigenius). This individual was found during a cleaning campaign of the bed of the river Tisza, most probably during the second half of the $19^{\text {th }}$ Century. Unfortunately, in both cases, the exact localities of the remains are not known. The age of these bones were considered to be infinite with regard to ${ }^{14} \mathrm{C}$ dating. As a knownage sample (K-Age), a larger tibia fragment of a Eurasian aurochs (Bos primigenius primigenius) from the Early Neolithic period was used, which had been offered by János Dani (Déri Museum, Debrecen). Based upon the circumstances of the archaeological excavation, its expected age falls into the period of Late Körös culture (Hencida-Gyürüszeg archaeological site, Eastern Hungary), which was also confirmed by ${ }^{14} \mathrm{C}$ age measurements of two other contemporaneous sites (Szentpéterszeg-Körtvélyes and Berettyóújfalu-Morotva-liget) (Gamba et al 2014). For the ultrafiltration tests, a modern pig (Sus scrofa domestica) bone (referred as Modern) was purchased at a butcher shop at the beginning of summer 2018. This bone was not identified by a zoologist but it is expected to be a leg bone (humerus or femur) of a 8-9 month old individual, which was slain 1 or 2 month before. After a thorough rinsing in ultrapure water, the bone was freeze-dried and the meat was removed by a scalpel.

\section{Bone preparation using modified Longin method (MLM)}

At HEKAL, all bone samples containing collagen are processed as follows. At the beginning of the pretreatment, all samples are visually inspected and all visible marks on its surface are noted along with the initial mass. After repeated ultrasonication in ultrapure water, the bones are dried at $60^{\circ} \mathrm{C}$ overnight. The outer surface of the bones is removed by thorough abrasion. Then, larger bone fragments are ground and sieved to get the adequate size fraction of $0.5-1.0 \mathrm{~mm}$. For chemical pretreatment, $500-1000 \mathrm{mg}$ (min. $100 \mathrm{mg}$ ) of the ground powder is placed in a special designed Omnifit TM glass column. These columns are used as flow cells in our semi-automatic system that was constructed for performing the ABA (acidbase-acid) cleaning method on bone samples (Molnár et al., 2013). At the end of the chemical pretreatment, the $\mathrm{pH}$ is adjusted to 3 to eliminate any ambient $\mathrm{CO}_{2}$ absorbed in the basetreatment step. Subsequently, the acid-insoluble collagen is transferred into a test tube containing $5 \mathrm{ml}$ of $\mathrm{pH} 3$ aqueous solution, and it is put into a block heater at $75^{\circ} \mathrm{C}$ for 24 hours. Dissolved gelatin is then filtered via a $2 \mu \mathrm{m}$ glass fibre filter (Milles AP20) into a 20 $\mathrm{mL}$ vial pre-cleaned by nitrogen gas, and after freezing, it is freeze-dried for at least 2 days.

Gelatin samples are then combusted using a modified sealed-tube combustion method where the sample and $\mathrm{MnO}_{2}$ reagent are together placed in a borosilicate test tube. After flame sealing, the closed tubes are placed in a muffle furnace at $550^{\circ} \mathrm{C}$ for at least $12 \mathrm{hr}$ to combust the gelatin. The $\mathrm{CO}_{2}$ gas produced is then transferred and purified from any other byproduct gases and carbon content quantified using a dedicated vacuum line (Janovics et al., 2018).

\section{Bone preparation using ultrafiltration (UF)}

Regarding the use of ultrafiltration, numerous aspects of its benefits and drawbacks have been presented and discussed in the literature. Bronk Ramsey et al. (2004) found 
evidence that the ultrafiltration method is a considerable advance in terms of removing environmental contamination and produces more accurate ages (mainly for bones of Paleolithic age) than less rigorous bone pretreatment methods. Nonetheless, the filters can contaminate the collagen with glycerol deriving from the surface of filters, but Brock et al. (2007) have shown that this humectant can effectively be removed applying a profound cleanup procedure before use. Furthermore, Hüls et al. (2009) have shown that the fragmentation of ultrafilter membrane itself, which is ancient in age, could also contaminate the filtrate fraction $(<30 \mathrm{kDa})$ but no significant contamination was seen in the supernatant fraction $(>30 \mathrm{kDa})$. However, this effect has not yet been independently confirmed by other laboratories (Wood 2010). As ${ }^{14} \mathrm{C}$ investigations regarding VIVASPIN $15 \mathrm{R}$ filters appear to give clear evidence for no contamination with either young or old carbon for both the filtrate and supernatant fractions (Hüls et al., 2009), so we used the ultrafilters of this type for our tests.

In all cases, the cleaning step occurred on the day before the ultrafiltration of the actual collagen samples. Briefly, the ultrafilters (VIVASPIN 15R, 30,000 MWCO HY, regenerated cellulose membrane) are filled with $15 \mathrm{~mL}$ of ultrapure water and centrifuged at $3500 \mathrm{rpm}$ for $15 \mathrm{~min}$. This step is repeated two more times. Then, the filters are completely filled with ultrapure water and ultrasonicated for at least 60 min followed by centrifuging $15 \mathrm{~mL}$ ultrapure water further two times. Our ultrafiltration protocol was set up based on other already tested protocols published in the peer-reviewed literature (Ramsey et al. 2004). The bone samples were treated in parallel using the MLM and ultrafiltration bone cleaning protocols. The two collagen extraction procedure are the same till to the point of filtration using $2 \mu \mathrm{m}$ syringe filters. At this point, the collagen solution is transferred to a pre-cleaned ultrafilter and centrifuged at $3000 \mathrm{rpm}$ for $15 \mathrm{~min}$. The filtrate (referred as UFB in the text) and supernatant (UFA) fractions were collected separately into individual $20 \mathrm{~mL}$ vials and were freeze-dried for 2 days. Subsequent combustion and $\mathrm{CO}_{2}$ cleaning steps are the same as described earlier for the non-ultrafiltered collage preparation.

\section{Applied analytical methods}

Carbon and nitrogen stable isotope measurements were calibrated by control measurements of IAEA 600 (caffeine) and sulfanilamide standards after every fifth unknown sample. Measurements were performed by a Thermo Finnigan Delta Plus XP isotope ratio mass spectrometer. Briefly, gelatin sub-samples $(\sim 0.3 \mathrm{mg})$ are packed into ultraclean aluminum cups and combusted by an elemental analyzer (EA, Fisons NA 1500). The C/N ratio, carbon and nitrogen stable isotope ratios are measured in the same run. The stable isotope results are expressed as delta value which is defined as follows: $\delta(\%)=\left(R_{\text {sample }} / R_{\text {reference- }}\right) * 1000$, where $R_{\text {sample }}$ and $\mathrm{R}_{\text {reference }}$ is the ${ }^{13} \mathrm{C} /{ }^{12} \mathrm{C}$ (or $\left.{ }^{15} \mathrm{~N} /{ }^{14} \mathrm{~N}\right)$ ratio in the sample and in the reference material, respectively. The overall uncertainty of the

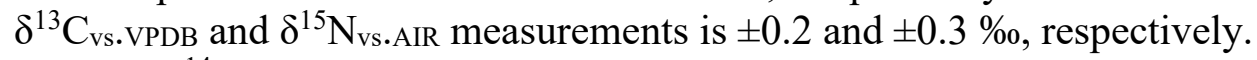

For ${ }^{14} \mathrm{C}$ dating by AMS, graphite targets from the purified $\mathrm{CO}_{2}$ samples were prepared using a customized sealed tube graphitization method (Rinyu et al. 2013). The ${ }^{14} \mathrm{C}$ measurements reported below were performed using the EnvironMICADAS AMS instrument at HEKAL (Molnár et al. 2013b). The overall measurement uncertainty for modern samples is $<3.0 \%$, including normalization, background subtraction, and counting statistics. The conventional ${ }^{14} \mathrm{C}$ ages were evaluated by the "Bats" software package (version 3.66; Wacker et al., 2010, Stuvier and Polach 1977). 
Evaluation of the bone procedural blank

The two bones of a steppe bison (hereafter ProBl_1 and ProBl_2) and the remains of a woolly mammoth (hereafter ProB1_3) were applied sequentially as internal blank samples during the studied two and a half year to assess the procedural background of our current bone preparation method (in total 82 graphite targets). In all cases, the blank samples were assumed to have an infinite age although this was not independently confirmed by archaeological findings or other dating methods. The amount of the extracted gelatins ranged from 10-100 $\mathrm{mg}$ while the mass of combusted gelatin scattered around $4 \mathrm{mg}$. For example, Wood et al. (2010) has suggested a new correction method to avoid the under-correction of large and overcorrection of very small samples. In our case, the radiocarbon ages of the three blank samples plotted as a function of the gelatin yield $(\mathrm{mg})$ does not show any significant correlation (max. $\mathrm{R}^{2}$ is 0.15 for ProBl_3) therefore we did not use any special gelatin yield dependent correction.

First, we studied the instrument background (InsBl) itself and compared it to the bone procedural blanks (ProBl, Figure 1/a). The instrument blanks are made from high purity fossil $\mathrm{CO}_{2}$ borehole gas (Linde Hungary, Répcelak) requiring no chemical pretreatment; the gas samples are just graphitized and AMS measured (Molnár et al., 2013). The long-term mean $\mathrm{F}^{14} \mathrm{C}$ for the instrument blank is around $0.0029 \pm 0.0007(\mathrm{n}=78,4$ outlier $)\left(\mathrm{F}^{14} \mathrm{C}\right.$ values quoted in this paper are all $\pm 1 \sigma)$. In each measurement batch (22 targets in total), three instrument blanks can be found of which mean value is subtracted from all the unknown samples measured in that certain run. Therefore, all the bone results presented in this paper have already been corrected for the instrument blanks but in case of the blank bones, the uncorrected values are also given. After discarding the apparent outlier results (indicated by circles and dots in Figure 1), bone blank samples coded as ProBl_1, ProBl_2 and ProBl_3 gave the following mean $\mathrm{F}^{14} \mathrm{C}$ and $\mathrm{SD}$ values: $0.0039 \pm 0.0012(\mathrm{n}=\overline{25}$, uncorrected: $0.006 \overline{8})$, $0.0054 \pm 0.0012(\mathrm{n}=19$, uncorr.: 0.0082) and 0.0043 $\pm 0.0013(\mathrm{n}=35$, uncorr.: 0.0074), respectively. As the mean data show, the corrected $\mathrm{F}^{14} \mathrm{C}$ value for the sample ProBl_2 is more than 0.001 higher than that of the other two blank samples. Assuming equal variance, this mean value is significantly different from the other two blanks (two sample t-test, $p$-value 0.1). Based upon archaeological aspects, the two samples should have the same age due to their finding in the same gravel pit. The difference may be caused by a procedural reason, i.e. the cleaning process of glassware of the bone preparation system was changed when we switched from ProBl_1 to ProBl_2. That time, a new decontamination detergent (Contrad 90) was introduced in the protocol instead of chromic acid. Finally, when we changed to the blank bone ProBl_3, the soap and chromic acid regents were already applied sequentially, thus the blank again achieved a lower value, close to the initial one. Despite the wider interquartile range of the ProBl_3 sample (relative to ProBl_1), there is no statistically significant difference in the SD of these samples (two sample F-test, p-value 0.1). 

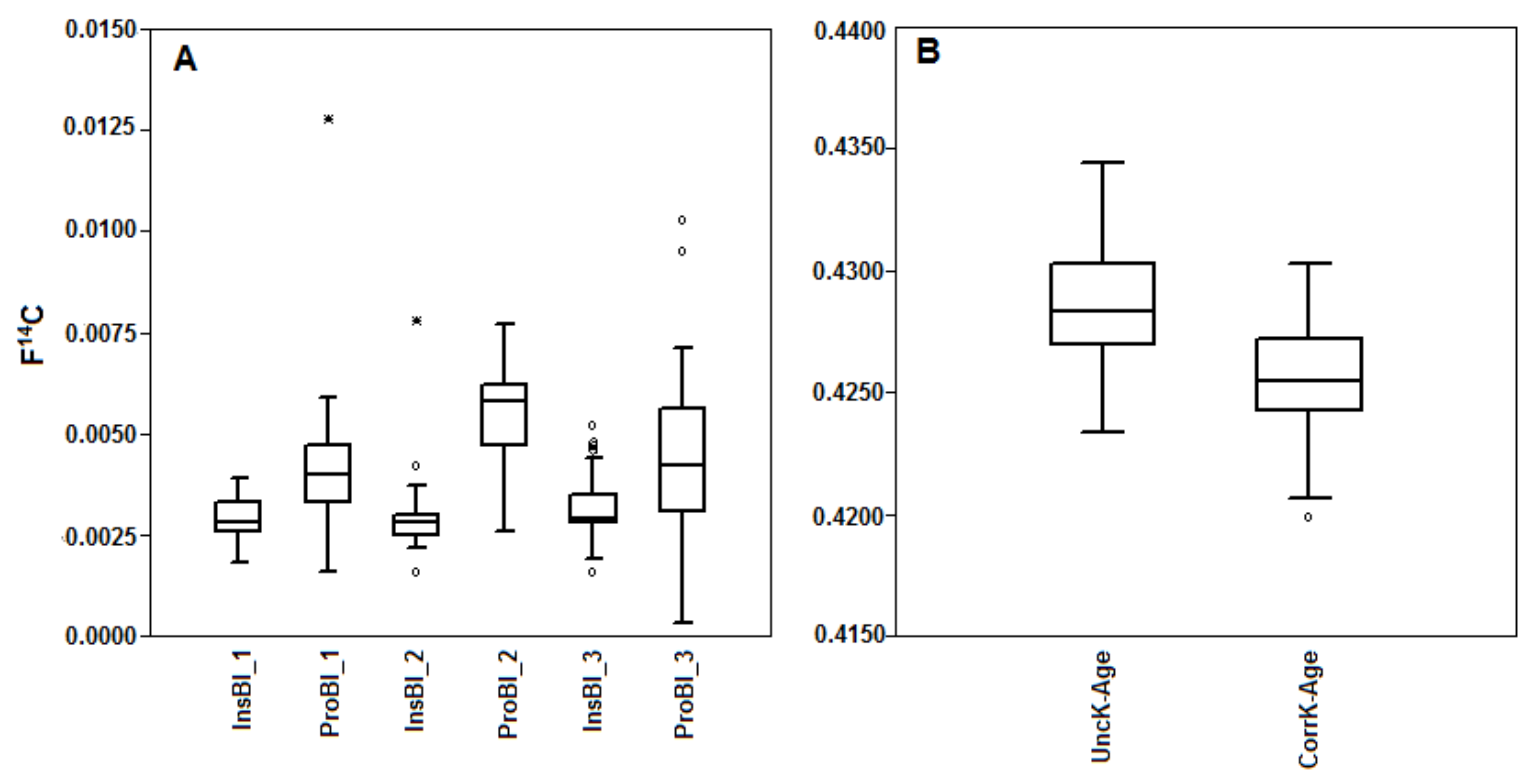

Figure 1/a Comparison of the mean $\mathrm{F}^{14} \mathrm{C}$ values for the associated instrumental (InsB1_1-3, fossil $\mathrm{CO}_{2}$ ) and procedural blanks (ProB1_1-3, fossil bones). The procedural bone blanks are already ins. blank corrected. $1 / \mathrm{b}$ Comparison of the mean $\mathrm{F}^{14} \mathrm{C}$ values of the known-age bone sample, before and after procedural blank correction (UncK-Age nad CorrK-Age, respectively). Circled and dotted results are those that are at least 1.5 or 3 times the interquartile range $(\mathrm{Q} 3-\mathrm{Q} 1)$ from the lower or upper quartile, respectively.

Comparing the long-term mean values of $0.0029 \pm 0.0007(n=78)$ and $0.0041 \pm 0.0013$ ( $\mathrm{n}=60$, ProBl_1 and ProBl_3 discarding the mean value of ProBl_2) for the instrument and corrected procedural blanks, respectively the former one significantly differs from the latter one (based on a two sample t-test and F-test, p-value 0.1). Dunbar et al. (2017) reported that the running mean $\mathrm{F}^{14} \mathrm{C}$ value of their modified Longin extraction method at SUERC is around $0.0030 \pm 0.0009$, which is higher than the value of a wood blank (Heidelberg tree) applied in parallel. They concluded that the complexity of collagen extraction procedure is unlikely to be solely responsible for the higher background contribution of bone measurements. Other studies have also indicated that the slight differences in the procedures undertaken by different staff members can also result in the variation of the final results (Fülöp et al., 2013; Dunbar et al. 2017). At our laboratory, bone preparation is performed by only one technician thus the higher bone blank is likely due to procedural (maybe mixed) factors. In the future, we would like to perform some physical tests regarding the filamentous structure of the gelatin (it has a large and adhesive surface relative to charcoal) whether or not it can be responsible for the increased background.

\section{Blank correction for bone samples}

The results regarding the procedural bone blanks point to the importance of an adequate background correction method, thus the $\mathrm{F}^{14} \mathrm{C}$ value of the blank sample measured in each bone measurement batch was used for blank correction of all the other bone samples to obtain more accurate ages. The instrumental-only and procedural blank-corrected mean $\mathrm{F}^{14} \mathrm{C}$ results for the known-age bone sample are shown in Figure 1/b. The replicated measurements of this bone offered an average raw $\mathrm{F}^{14} \mathrm{C}$ value of $0.4286(\mathrm{n}=70)$, which corresponds to a radiocarbon age of $6806 \mathrm{BP}$. The mean measurement uncertainty obtained by the Bats software is around $0.0017 \mathrm{~F}^{14} \mathrm{C}$ (30 yrs). Although the raw uncertainty of the AMS measurements is of the correct magnitude, it does not evidently account for the entire variation of the ${ }^{14} \mathrm{C}$ results. If 
we look at the standard deviations of 0.0020 and 0.0022 (40 yrs) related to the procedural blank corrected and uncorrected $\mathrm{F}^{14} \mathrm{C}$ values, respectively, these better characterize the corrected result is identical in magnitude with the uncorrected one, but the mean value is a slightly lower. Moreover, the SD of blank samples is also very similar that confirms the magnitude of the estimated uncertainty. We applied the following classical mass-balance equation for contamination correction:

$$
\mathrm{F}^{14} \mathrm{C}_{\text {measured }}{ }^{*} \mathrm{~m}_{\text {sample }+ \text { cont }}=\mathrm{F}^{14} \mathrm{C}_{\text {sample }}{ }^{*} \mathrm{~m}_{\text {sample }}+\mathrm{F}^{14} \mathrm{C}_{\text {cont }}{ }^{*} \mathrm{~m}_{\text {cont }}
$$

where, $\mathrm{F}^{14} \mathrm{C}$ and $\mathrm{m}$ represents the specific ${ }^{14} \mathrm{C}$ activity and mass of the sample and contamination, respectively. Based on the expected and measured mass and ${ }^{14} \mathrm{C}$ data of the blank sample, the mass of the contaminant can be calculated and applied for the unknown samples. As other labs have noted, the contamination added in the laboratory is usually assumed to be modern in age (Vogel et al. 1987). This modern carbon appears to contaminate the bone blank samples with similar amounts as the unknown samples since all samples are handled in the same way. The blank-corrected $\mathrm{F}^{14} \mathrm{C}$ value of this sample is $0.4256 \pm 0.0020$ corresponding to a date $6860 \mathrm{BP}$, indicating that this sample is only slightly affected by modern contaminating carbon. The majority of bone samples processed in the laboratory are of Neolithic or younger age, thus the blank correction does not shift significantly the results but these slight changes can gain greater importance in the Paleolithic range.

Ultrafiltration tests on bone samples

The ultrafiltration protocol was tested on our three internal standard bones of different ages, to see if any contamination remains in the samples (soil-derived) after chemical pretreatment or is introduced during the ultrafiltration step. The results are shown in Table 1. Ultrafiltration is a widely-used procedure for better purification of collagen but due to the risk of contamination derived from the surface of membranes, the filter requires thorough cleaning before use. To check whether or not any supposed humectants come from the surface of the filters and influence the collagen, IAEA-C7 (nominal $\delta^{13} \mathrm{CPDB}_{\mathrm{PD}}$ and $\mathrm{F}^{14} \mathrm{C}$ values are $-14.48 \pm 0.21$ and $0.4953 \pm 0.0012$, respectively) and IAEA-C8 (nominal $\delta^{13} \mathrm{CPDB}_{\mathrm{PD}}$ and $\mathrm{F}^{14} \mathrm{C}$ values are $-18.31 \pm 0.11$ and $0.1503 \pm 0.0017$, respectively) oxalic acid reference samples were also prepared in the test process, in parallel with bone samples. As the oxalic acid (dissolved in ultrapure water) has a molecule weight less than $30 \mathrm{kDa}$, only the filtrate fraction passing through the filters could be ${ }^{14} \mathrm{C}$ dated. According to our assumption, if the humectant has an effect on the filtrate fraction of bones, the supernatant fraction would show the contamination as well. However, if the filtrate fraction is confirmed to have no significant contamination present, the supernatantt fraction above the filter can also be regarded as contamination free, as Hüls et al., (2009) has suggested.

Looking at the carbon and nitrogen stable isotope data $\left(\delta^{13} \mathrm{C}, \delta^{15} \mathrm{~N}\right)$ there are no significant differences between the values of the Longin and ultrafiltration methods (Table 1). The values obtained for the IAEA C7 and C8 standards are also in good agreement with the nominal values in $1 \sigma$ range. The $\% \mathrm{C}$ content, $\% \mathrm{~N}$ content and $\mathrm{C} / \mathrm{N}$ data for the tested gelatin samples could be indicators for the poorly preserved or contaminated gelatins. We cannot observe significant differences in the values between the two preparation methods but the high $\mathrm{C} / \mathrm{N}$ ratios might be indicative for the not too well-preserved collagen. In case of the ProBl_3 sample prepared by the Longin method, the $\mathrm{C} / \mathrm{N}$ ratio is around 4.0 that can be indicative of some extra carbon-containing contamination in the gelatin. However, both of the filtrate and supernatant fractions yielded similar values (3.4-4.1) for the ultrafiltered materials, 
thus we can conclude that the high ratios out of the accepted range are not caused by contaminants having been collected in either fraction. The $\mathrm{C} / \mathrm{N}$ ratios of the known-age sample is also slightly higher than the conventionally accepted value (2.9-3.5), but visual

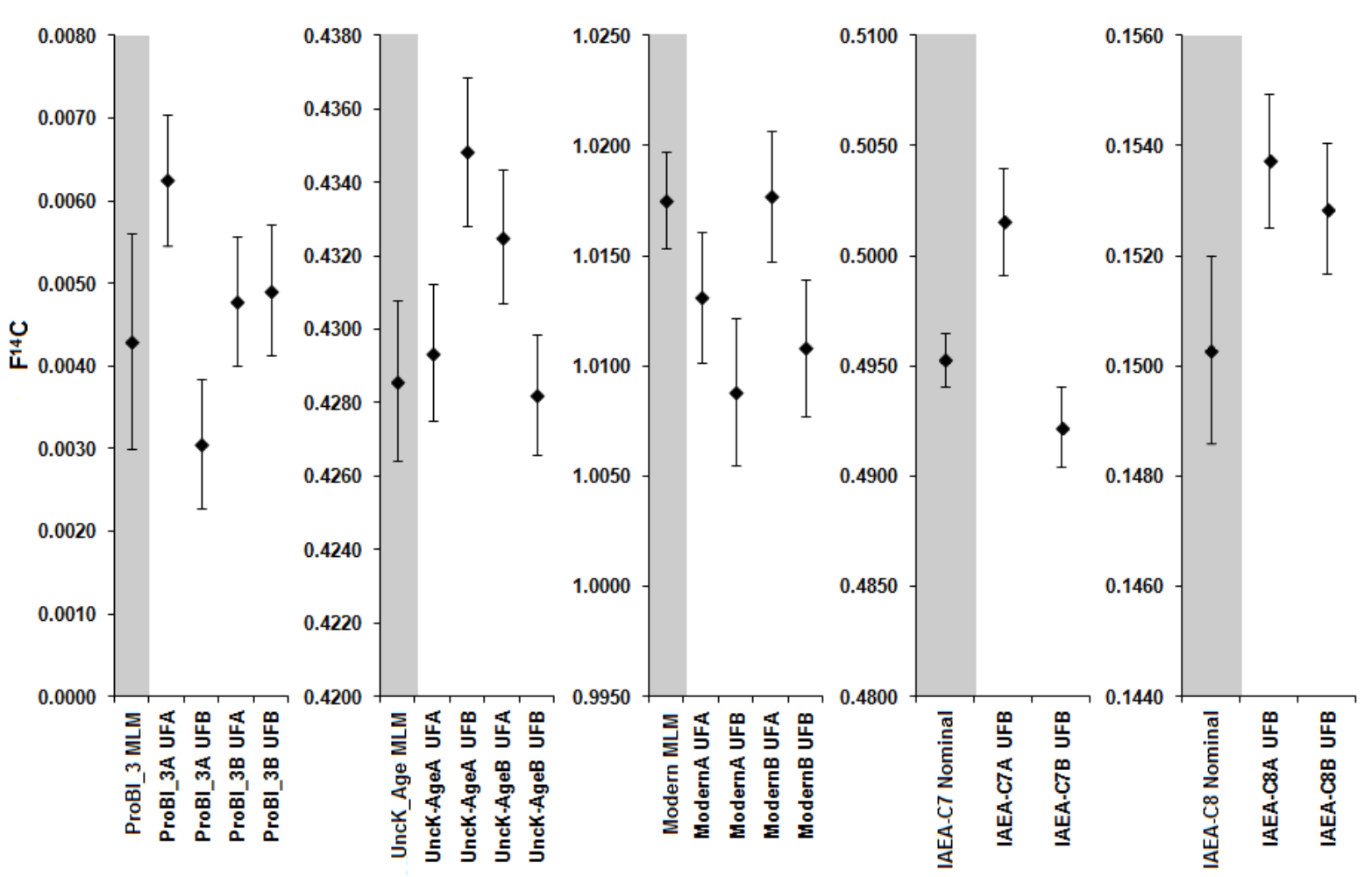

Figure 2 Comparison of the Longin and ultrafiltration methods using bone samples of different $\mathrm{F}^{14} \mathrm{C}$ values. The grey bars represents the results obtained by our current method. UFA and UFB denote the ultrafiltred supernatant and filtrate fractions, respectively.

Regarding the ${ }^{14} \mathrm{C}$ data, the procedural blank sample (ProBl_3) has regularly been prepared using our current method for two and half years and its long-term mean $\mathrm{F}^{14} \mathrm{C}$ value of $0.0043 \pm 0.0013$ is used in the comparisons. The mean values for the ultrafiltered supernatant (UFA) and filtrate (UFB) fractions are $0.0055 \pm 0.0010$ and $0.0040 \pm 0.0013$, respectively, which are very similar to each other and agree in $1 \sigma$ uncertainty range. Gelatin extracted using the ultrafiltration protocol produces similar results, suggesting that the bone is not contaminated appreciably with young carbon. K-Age samples (with an age around one ${ }^{14} \mathrm{C}$ half life) show a mean $\mathrm{F}^{14} \mathrm{C}$ value of $0.4286 \pm 0.0022$ (without ultrafiltration). The mean values for the ultrafiltered supernatant and filtrate fractions are $0.4310 \pm 0.0022$ and $0.4315 \pm 0.0047$, respectively, which are also very similar to each other and to the conventional value. These ultrafiltered samples were measured in different measurement batches so the external uncertainty (SD) of different measurements can also be studied. This suggests that the ultrafilters do not appreciably contaminate the samples with young carbon either. The mean $\mathrm{F}^{14} \mathrm{C}$ value for the duplicated modern pig samples prepared conventionally and corrected for the measurement blank is $1.0175 \pm 0.0012$. The mean $\mathrm{F}^{14} \mathrm{C}$ values obtained for the supernatant and filtrate fractions of the duplicated samples ultrafiltered are 1.0154 \pm 0.0032 and $1.0098 \pm 0.0014$, respectively. Seemingly, the filtrate fraction values are lower than that of the supernatant fraction. This could be an indication that the filter humectant contains a small amount of "old carbon" (having no large effect on the supernatant fraction) but this was not 
confirmed by the results of the known-age sample. The mean value of the samples prepared using our current method is effectively identical with the mean of supernatant fraction within the uncertainty range; moreover, it also does not differ from the mean of the filtrate fraction. Unfortunately, we do not yet have sufficient measurements for statistical tests on the modern bone material.

Table 1 Result of the analytical measurements performed on the bone samples included in the 367 ultrafiltration tests. The uncertainty for $\delta^{13} \mathrm{C}$ and $\delta^{15} \mathrm{~N}$ measurements are \pm 0.2 and $\pm 0.3 \%$, respectively.

\begin{tabular}{cccccccc}
\hline Sample code & $\boldsymbol{\delta}^{13} \mathbf{C}$ & $\delta^{15} \mathbf{N}$ & $\% \mathbf{C}$ & $\% \mathbf{N}$ & $\mathbf{C} / \mathbf{N}$ & $\mathbf{F}^{14} \mathbf{C}$ & unc. \\
\hline ProBI_3 MLM & -21.7 & 10.2 & 50.3 & 14.4 & 4.0 & 0.0043 & 0.0013 \\
ProBI_3A UFA & -21.7 & 10.3 & 43.0 & 13.0 & 3.9 & 0.0063 & 0.0008 \\
ProBI_3A UFB & -21.8 & 10.4 & 46.3 & 13.6 & 4.0 & 0.0031 & 0.0008 \\
ProBI_3B UFA & -21.7 & 10.2 & 44.2 & 12.6 & 4.1 & 0.0048 & 0.0008 \\
ProBI_3B UFB & -21.7 & 10.4 & 45.6 & 15.7 & 3.4 & 0.0049 & 0.0008 \\
\hline K-Age MLM & $-20-7$ & 6.2 & 44.8 & 13.5 & 3.9 & 0.4286 & 0.0022 \\
K-AgeA UFA & -20.7 & 6.5 & 45.1 & 15.4 & 3.4 & 0.4294 & 0.0019 \\
K-AgeA UFB & na & $\mathrm{Na}$ & na & na & na & 0.4348 & 0.0020 \\
K-AgeB UFA & na & $\mathrm{Na}$ & na & na & na & 0.4325 & 0.0018 \\
K-AgeB UFB & -20.8 & 6.5 & 42.7 & 13.9 & 3.6 & 0.4282 & 0.0016 \\
\hline Modern MLM & -18.1 & 3.2 & 44.9 & 15.2 & 3.0 & 1.0175 & 0.0012 \\
ModernA UFA & -17.8 & 3.2 & 46.2 & 15.8 & 3.4 & 1.0131 & 0.0030 \\
ModernA UFB & na & $\mathrm{Na}$ & na & na & na & 1.0088 & 0.0034 \\
ModernB UFA & -17.9 & 3.4 & 41.9 & 15.5 & 3.2 & 1.0177 & 0.0029 \\
ModernB UFB & -18.0 & 3.3 & 38.3 & 14.7 & 3.0 & 1.0109 & 0.0031 \\
\hline IAEA-C7 Nominal & -14.5 & $\mathrm{Na}$ & 19.7 & na & na & 0.4953 & 0.0012 \\
IAEA-C7A UFB & -14.7 & $\mathrm{Na}$ & 18.0 & na & na & 0.5016 & 0.0024 \\
IAEA-C7B UFB & -14.7 & $\mathrm{Na}$ & 18.9 & na & na & 0.4923 & 0.0018 \\
\hline IAEA-C8 Nominal & -18.3 & $\mathrm{Na}$ & 19.7 & na & na & 0.1503 & 0.0017 \\
IAEA-C8A UFB & -18.5 & $\mathrm{Na}$ & 18.3 & na & na & 0.1537 & 0.0012 \\
IAEA-C8B UFB & -18.5 & $\mathrm{Na}$ & 19.8 & na & na & 0.1529 & 0.0012 \\
\hline
\end{tabular}

If we look at the mean $\mathrm{F}^{14} \mathrm{C}$ value of the filtrate fraction of IAEA-C7 standard samples, we can see a value of $0.4969 \pm 0.0066$ that is slightly higher than the nominal value $(0.4953 \pm 0.0012)$ but is still within $2 \sigma$. These samples were measured in different measuring batches, thus the higher SD in an indication of the external error. The IAEA-C8 standard samples gave a mean value of $0.1533 \pm 0.0006$, which is 0.003 higher than the nominal value $(0.1503 \pm 0.0017)$, indicating a small modern effect during the filtration process. The results of some other studies showed that ultrafiltration did not yield statistically different ages in comparison to the values obtained for subsamples treated by the Lognin method. It appears that the ultrafiltration method has reached a point where sample size and AMS precision are no longer the limiting factors; rather, human error during pretreatment and sample handling plays a key role in delivering the expected accuracy of bone ${ }^{14} \mathrm{C}$ dating (Fülöp et al., 2013). Our results measured for our test bones of different radiocarbon ages also show that the mean values for both the modified Longin and the ultrafiltration gelatin extraction methods are indistinguishable, but we will continue our tests, involving bones having bad preservation or low collagen yield. The differences in ages obtained (at $1 \sigma$ level) could be due to procedural factors, which has been overlooked, or AMS measurement variability, as we have seen in the case of background and known-age sample measurements.

\section{Conclusions}


In the last two and a half years, numerous procedural blank and known-age bones were prepared and measured at HEKAL. In this paper, we tried to evaluate mathematically the results and in addition, an ultrafiltration protocol was also tested. In the first section, we showed that our internal procedural blank samples give a background of around $0.005 \mathrm{~F}^{14} \mathrm{C}(\sim$ $42.500 \mathrm{BP})$ or even better due to the efficient bone pretreatment protocol. A good reproducibility was confirmed by the results of internal laboratory known-age bones as well, where the standard deviation of the sample is better than 0.0025 in $\mathrm{F}^{14} \mathrm{C}$. We presume that any variation is probably caused by natural variability during the sample pretreatment. We have also demonstrated that the actual date of a sample with a Holocene age becomes slightly older after blank correction.

In the second section, we evaluated a new ultrafiltration protocol, which was inserted into our bone processing protocol. The selected bones of different ages were processed in parallel using our modified Longin and ultrafiltration preparation methods, but no notable differences were obtained in $2 \sigma$ uncertainty range. The results suggest that our modified Longin method remove properly the contamination out of the selected bones but we will continue our tests, involving bones having bad preservation or low collagen yield.

\section{Acknowledgments}

The research was supported by the European Union and the State of Hungary, cofinanced by the European Regional Development Fund in the project of GINOP-2.3.2-152016-00009 'ICER'. This work was done under the auspices of IAEA (International Atomic Energy Agency) in the frame of the CRP (Coordinated Research Projects): Enhancing Nuclear Analytical Techniques to Meet the Needs of Forensics Sciences. The paper was supported by the Momentum Mobility research project of the Hungarian Academy of Sciences. In addition, a special thanks to Renáta Gönczi and Krisztina Szathmári for the careful sample handling and preparation and to M. Daróczi-Szabó for the zoological determination.

\section{References}

Arslanov KA, Svezhentsev YS. 1993. An improved method for radiocarbon dating fossil bones. Radiocarbon 35(3):387-391.

Brock F, Ramsey CB, Higham T. 2007. Quality assurance of ultrafiltered bone dating. Radiocarbon 49(2): 187-192.

Bronk Ramsey C, Higham T, Bowles A, Hedges R. 2004. Improvements to the pretreatment of bone at Oxford. Radiocarbon 46(1):155-163.

Brown TA, Nelson DE, Vogel JS, Southon JR. 1988. Improved collagen extraction by modified Longin method. Radiocarbon 30(2):171-177.

Dunbar E, Naysmith P, Cook GT, Scott EM, Xu S, Tripney BG. 2017. Investigation of the analytical F14C bone background value at SUERC. Radiocarbon 59(5):1463-1473.

Fülöp RH, Heincze S, John S, Rethenmeyer J. 2013. Ultrafiltration of bone samples is neither the problem nor the solution. Radiocarbon 55(2-3):491-500. 
Gamba C, Jones ER, Teasdale MD, McLaughlin RL, Gonzalez-Fortes G, Mattiangeli V, 438 Domboróczki L, Kővári I, Pap I, Anders A, Whittle A, Dani J, Raczky P, Higham TF, 439 Hofreiter M, Bradley DG, Pinhasi R. 2014. Genome flux and stasis in a five millennium

Hüls CM, Grootes PM, Nadeau M-J. 2007. How clean is ultrafiltration cleaning of bone collagen? Radiocarbon 49(2):193-200.

Hüls CM, Grootes PM, Nadeau M-J. 2009. Ultrafiltration: boon or bane? Radiocarbon 51(2):613-626.

Higham TFG, Jacobi RM, Bronk Ramsey C. 2006. AMS radiocarbon dating of ancient bone using ultrafiltration. Radiocarbon 48(2):179-195.

Janovics R, Futó I, Molnár M. 2018. Sealed tube combustion method with $\mathrm{MnO}_{2}$ for $\mathrm{AMS}$ ${ }^{14} \mathrm{C}$ measurements. Radiocarbon 60 (5): 1347-1355.

Kalicz N. 2012. Szentpéterszeg-Körtvélyes. In: The First Neolithic Sites in Central/SouthEast European Transect. Vol. III. The Körös Culture in Eastern Hungary. Ed.: Anders, A Siklósi, Zs. Oxford. 77-84.

Longin R. 1971. New method of collagen extraction for radiocarbon dating. Nature 230(5291):241-242.

Molnár M, Rinyu L, Janovics R, Major I, Veres M. 2012. Introduction of the new AMS C-14 laboratory in Debrecen. Archeometriai Mühely 9(3):147-160.

Molnár M, Janovics R, Major I, Orsovszki J, Gönczi R, Veres M, Leonard AG, Castle SM, Lange TE, Wacker L, Hajdas I, Jull AJT. 2013. Status report of the new AMS ${ }^{14} \mathrm{C}$ sample preparation lab of the Hertelendi Laboratory of the Environmental Studies (Debrecen, Hungary). Radiocarbon 55(2-3):665-676.

Molnár M, Rinyu L, Veres M, Seiler M, Wacker L, Synal H-A. 2013b. EnvironMICADAS: a mini ${ }^{14} \mathrm{C}$ AMS with enhanced Gas Ion Source Interface in the Hertelendi Laboratory of Environmental Studies (HEKAL), Hungary. Radiocarbon 55 (2-3):338-344.

Naysmith P, Dunbar E, Scott EM, Cook GT, Tripney BG, Brown R. 2017. Preliminary results for estimating the bone background uncertainties at SUERC using statistical analysis. Radiocarbon. 59 (5): 1579-1587.

Rinyu L, Molnár M, Major I, Nagy T, Veres M, Kimák Á, Wacker L, Synal H-A. 2013. Optimization of sealed tube graphitization method for environmental ${ }^{14} \mathrm{C}$ studies using MICADAS. Nuclear Instruments and Methods in Physics Research B 294(1):270-275.

Saliège J-F, Person A, Paris F. 1995. Preservation of 13C/ 12C original ratio and 14C dating of the mineral fraction of human bones from Saharan tombs, Niger. Journal of Archaeological Science 22(2):301-312.

Stuiver M, Polach HA. 1977. Discussion: reporting of 14C data. Radiocarbon 19(3):355-363. 
van Klinken GJ, Hedges REM. 1995. Experiments on collagen-humic interactions: speed of 487 humic uptake, and effects of diverse chemical treatments. Journal of Archaeological Science 488 22(2):263-270.

490 Vogel JS, Nelson DE, Southon J. 1987. 14C background levels in an AMS system. 491 Radiocarbon 29(3):323-333.

Wacker L, Christl M, Synal H-A. 2010. Bats: A new tool for AMS data reduction. Nuclear 494 Instruments and Methods in Physics Research B 268:976-979.

Wood RE, Bronk Ramsey C, Higham TFG. 2010. Refining background corrections for 497 radiocarbon dating of bone collagen at ORAU. Radiocarbon 52(2):600-611.

498 